
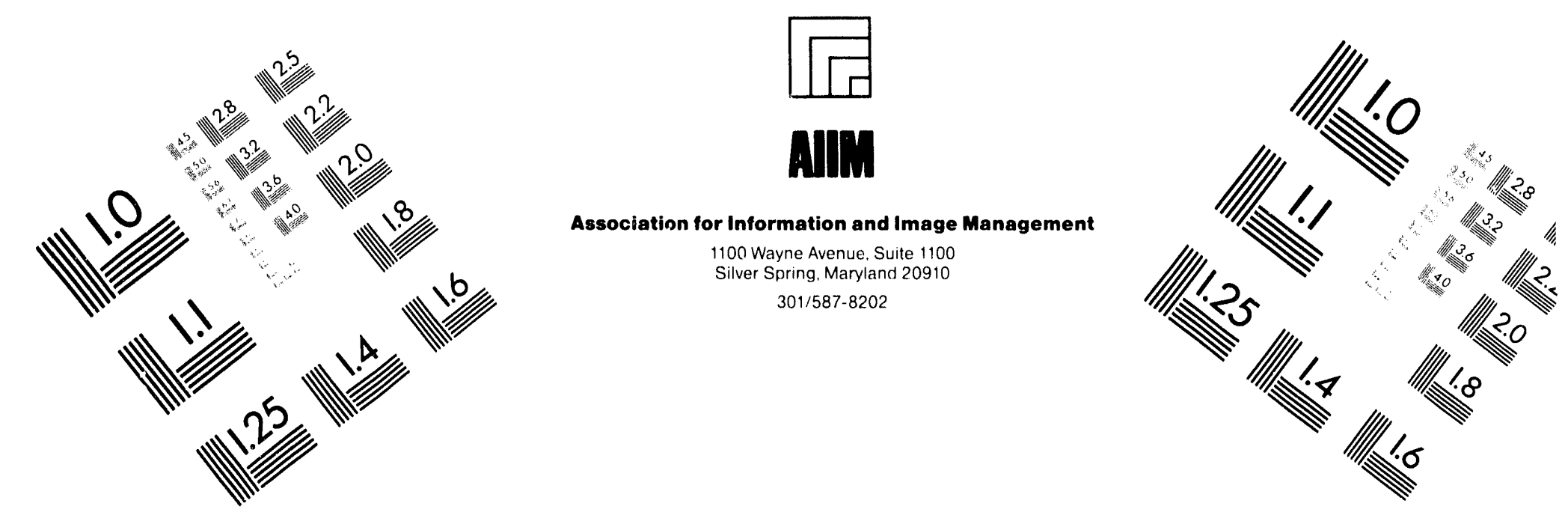

Centimeter

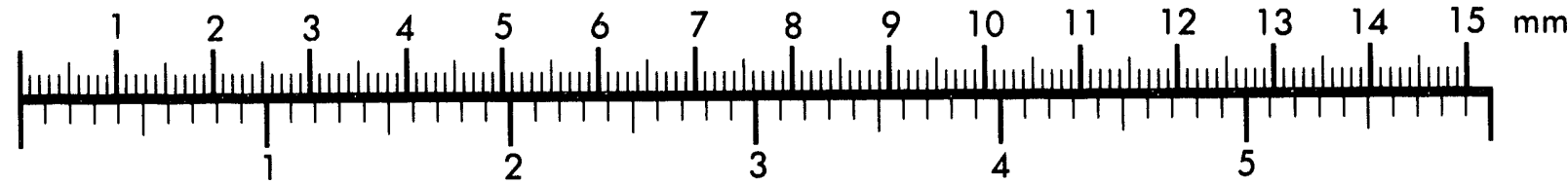

Inches
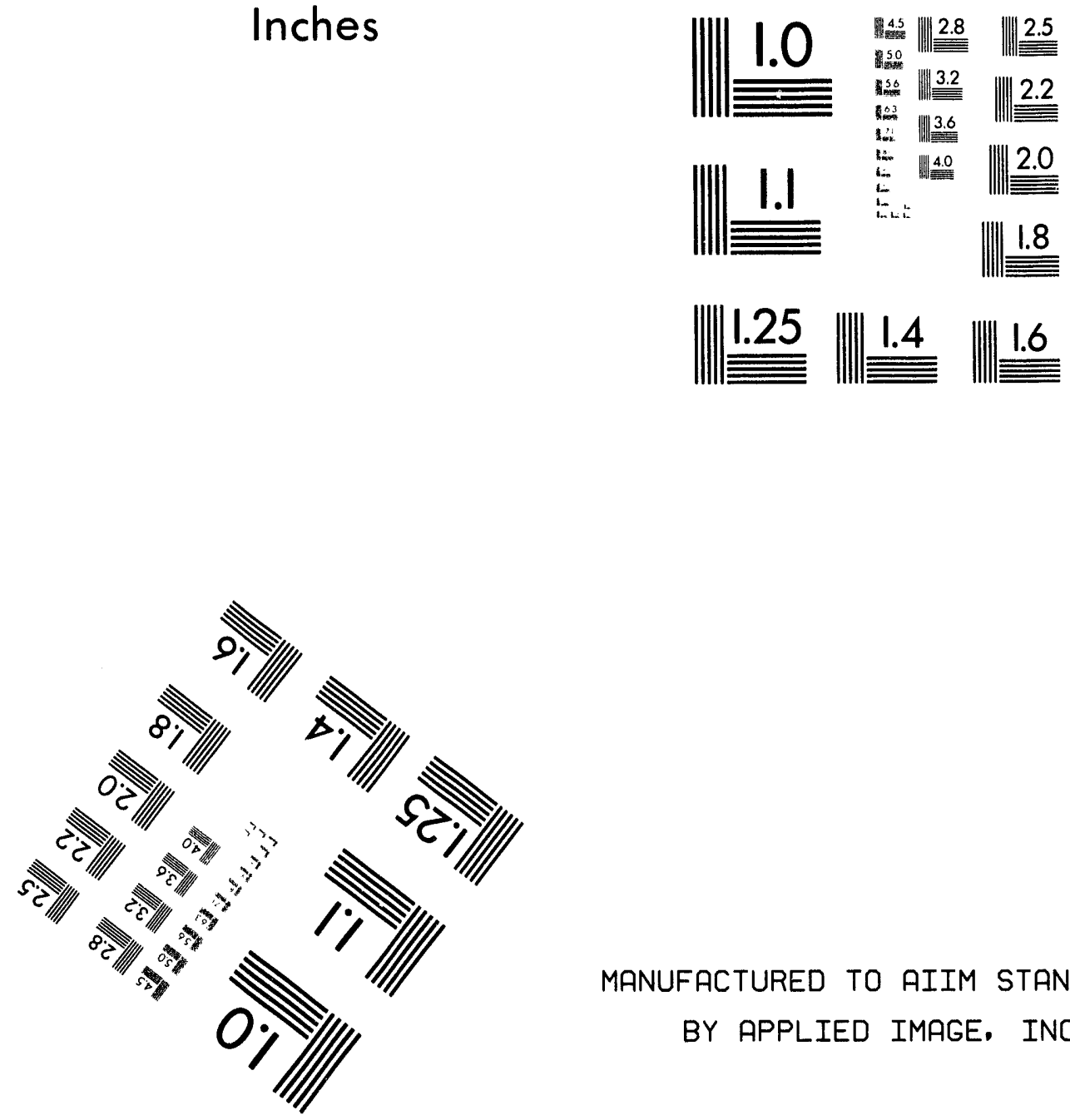

MANUFACTURED TO AIIM STANDARDS

BY APPLIED IMAGE, INC.

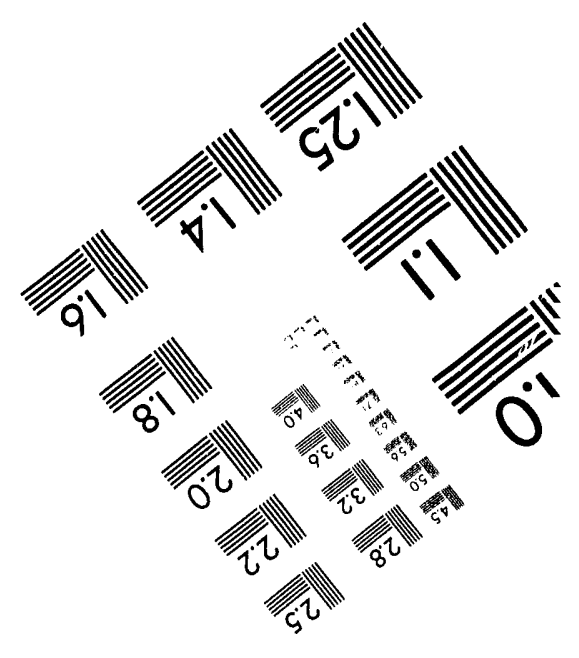



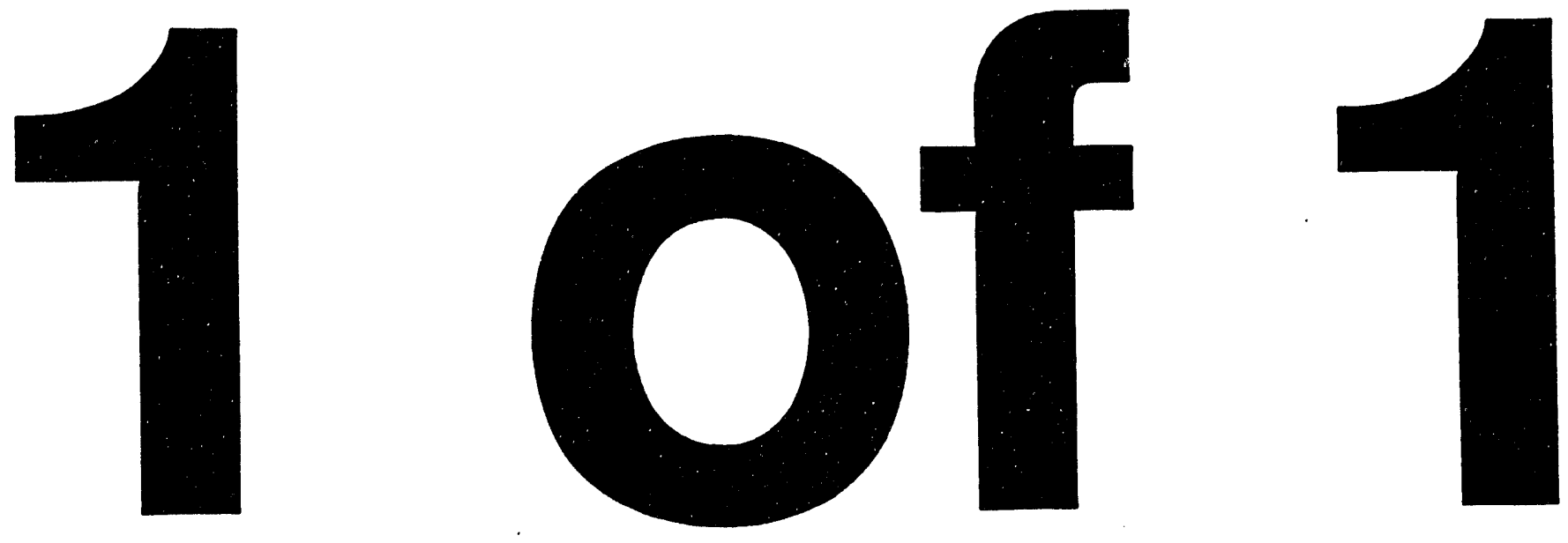


\title{
The Transformation of Organlc Amines by Transition Metal Cluster Compounds
}

DEF/ER/13296-10

\section{Progress Report}

\section{3-1994}

\author{
Dr. Richard D. Adams \\ Professor of Chemistry
}

\author{
DEPARTMENT OF CHEMISTRY \\ UNIVERSITY OF SOUTH CAROLINA \\ COLUMBIA, SC 29208
}

January 1994

PREPARED FOR THE U.S. DEPARTMENT OF ENERGY UNDER GRANT DE-FG09-84ER13296 


\section{-.Contents of Progress Report--}

A) Results in 1993.

1) Insertion of an Alkynes into Rhenium-Rhenium Single Bonds

and the Organic Chemistry of Dimetalated Olefins.

2) Ring Opening of Cyclic Thioethers

3) Studies of the Cyclobutyne Ligand.

4) Energy Storage in Metal Clusters

B) Studies planned for the next budget year.

1) Insertion of an Alkynes into Metal - metal Single Bonds and new Organic Chemistry of Dimetalated Olefins.

2) Studies of the Cyclobutyne Ligand.

3) Energy Storage in Metal Clusters

C) Publications for the year 1993.

D) Current and Pending Support.

E) Statement of Residual Funds.

F) Annual Budget. June 1, 1994 - May 31, 1995.

"This report was prepared as an account of work sponsored by an agency of the United States Government. Neither the United States Government nor any agency thereof, nor any of their employees, makes any warranty, express or implied, or assumes any legal liability or responsibility for the accuracy, completeness, or usefulness of any information, apparatus, product, or process disclosed, or represents that its use would not infringe privately owned rights. Reference herein to any specific commercial product, process, or service by trade name, trademark, manufacturer, or otherwise, does not necessarily constitute or imply its endorsement, recommendation, or favoring by the United States Government or any agency thereof. The views and opinions of authors expressed herein do not necessarily state or reflect those of the United States Government or any agency thereof." 


\section{A) Results in 1993.}

1) Insertion of an Alkynes Into Rhenium-Rhenium Single Bonds and the Organic Chemistry of Dimetalated Olefins.

In 1992 we discovered the first example of the insertion of an alkyne into a metal-metal bond in the reaction of $\mathrm{HC} \equiv \mathrm{CCO}_{2} \mathrm{Me}$ with $\mathrm{Re}_{2}(\mathrm{CO})_{9}(\mathrm{NCMe})$, 1. Interestingly, the dimetalated olefin product exhibited a trans-or E-stereochemistry. In 1993 we extended our investigations into the nature of these insertion reactions by investigating the reaction of the dicarboxylate acetylene, $\mathrm{EtO}_{2} \mathrm{CC} \equiv \mathrm{CCO}_{2} \mathrm{Et}$ with 1. The new complex $\operatorname{Re}(\mathrm{CO})_{4}\left[\mu-Z-\left(E t O_{2} \mathrm{C}\right) \mathrm{C}=\mathrm{C}\left(\mathrm{CO}_{2} \mathrm{Et}\right)\right] \mathrm{Re}(\mathrm{CO})_{5}, 2$ was the initial product. It was found to be a cis- or Z-dimetalated olefin complex formed by the insertion of the alkyne into the rhenium-rhenium bond. One of the carboxylate groups is coordinated to one of the rhenium atoms through the carbonyl oxygen atom to form a four membered metallacyclic ring. When irradiated, compound 2 was isomerized to the trans or E-complex $\operatorname{Re}(\mathrm{CO})_{4}\left[\mu-E-\left(\mathrm{EtO}_{2} \mathrm{C}\right) \mathrm{C}=\mathrm{C}\left(\mathrm{CO}_{2} \mathrm{Et}\right)\right] \operatorname{Re}(\mathrm{CO})_{5}, 3$ and the carbonyl oxygen atom of the carboxylate group became coordinated to the other rhenium atom to form a five membered metallacyclic ring. Decarbonylation of 3 by irradiation yielded the new complex $\operatorname{Re}(C O)_{4}[\mu-E$ $\left.\left(\mathrm{EtO}_{2} \mathrm{C}\right) \mathrm{C}=\mathrm{C}\left(\mathrm{CO}_{2} \mathrm{Et}\right)\right] \mathrm{Re}(\mathrm{CO})_{4}, 4$ by coordination of the oxygen atom of the second carboxylate group. All complexes were characterized by single crystal $x$-ray diffraction analyses.

The mechanism that interrelates the alkyne insertion products in this study is shown in Scheme 1. In the first step the alkyne simply displaces the NCMe ligand to form an intermediate species such as $A$, which has not yet been observed, in which the alkyne is simply $\pi$-bonded to one metal atom. As the alkyne ligand begins to form a bonding 
interaction with the second metal atom, the metal - metal bond begins to develop a heteropolar character, species B. The carbonyl oxygen atom of one of the carboxylate groups is coordinated to the first metal atom to form the four membered metallacyclic ring and induce the cleavage of the metal - metal bond to yield 2. A species similar to 2 might also be traversed in the course of the insertion of $\mathrm{HC} \equiv \mathrm{CCO}_{2} \mathrm{Me}$ into the $\mathrm{Re}-\mathrm{Re}$ bond of 1 , but that species can not be stablized by interaction with the $\mathrm{CO}_{2} \mathrm{Me}$ group since the carbon containing that group must be bonded to the $\operatorname{Re}(\mathrm{CO})_{5}$ grouping. The conversion 2 to 3 occurs photolytically. This could occur via a diradical intermediate such as $\mathbf{C}$ formed as a result of excitation of the $\pi$-electrons in the C - C double bond. Once a species with the E-geometry such as $D$ is formed, the formation of 3 is occurs since the five membered metallacyclic ring will be much more stable than a strained four membered metallacyclic ring. The decarbonylation of 3 to 4 is a simple process of CO loss followed by the formation of a second five membered metallacyclic ring by using the second carboxylate group of the alkyne. The cis-insertion of alkynes into metal - metal bonds may resemble the important insertion of alkynes into metal - carbon and metal - hydrogen bonds. Further studies are in progress. 


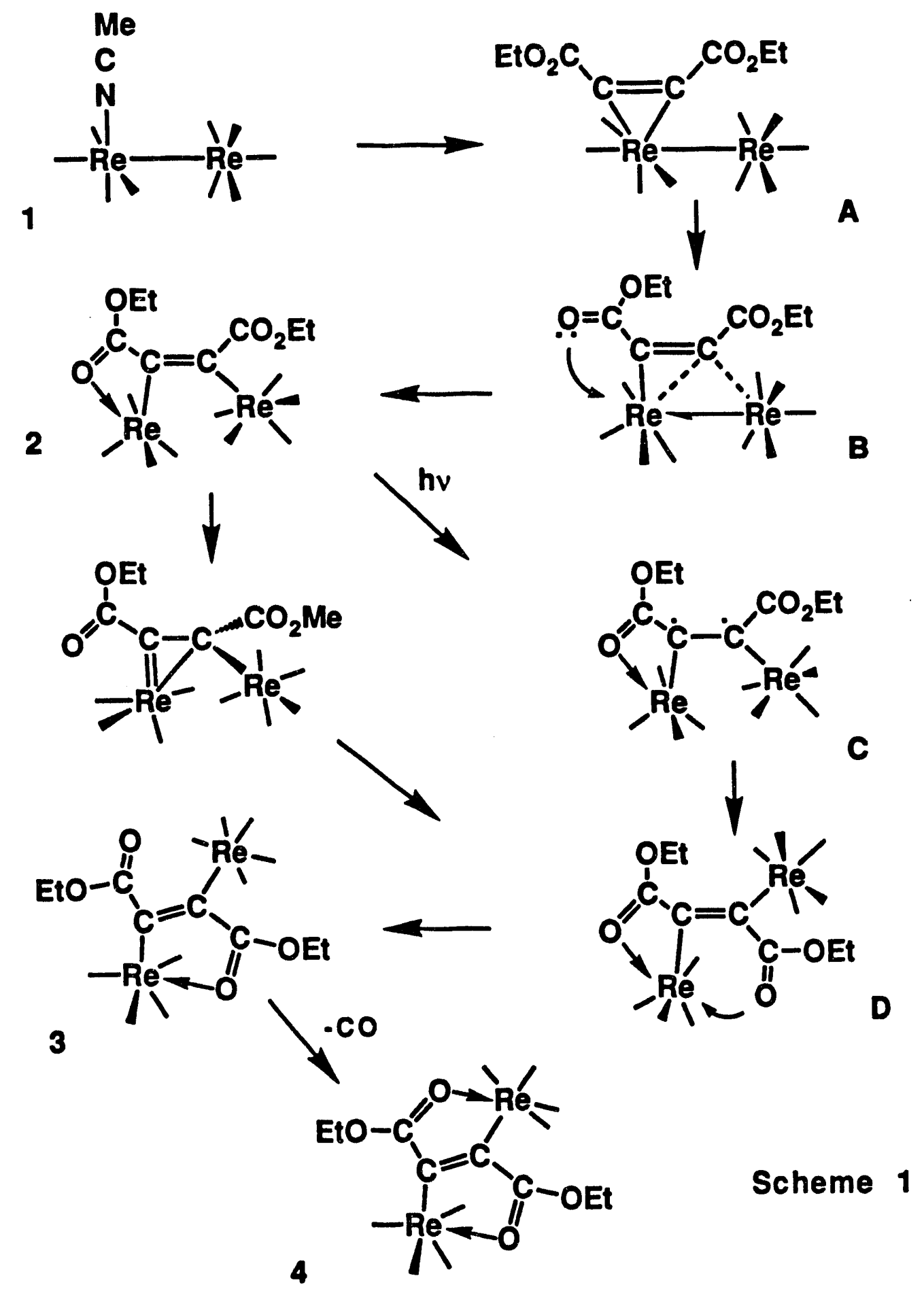

We have also investigated some aspects of the organic chemistry of the complex $(\mathrm{OC})_{4} \mathrm{Re}\left[\right.$ trans $\left.-\mu-\mathrm{HC}=\mathrm{C}\left(\mathrm{CO}_{2} \mathrm{Me}\right)\right] \mathrm{Re}(\mathrm{CO})_{5}, 5$, through its conversion to the reactive acetonitrile complex $(\mathrm{OC})_{4} \mathrm{Re}[\operatorname{trans}-\mu$ $\mathrm{HC}=\mathrm{C}\left(\mathrm{CO}_{2} \mathrm{Me}\right) \mathrm{Re}(\mathrm{CO})_{4}(\mathrm{NCMe}), 6$. Under an atmosphere of $\mathrm{CO}$, complex 2 
reacts with $\mathrm{HC} \equiv \mathrm{CCO}_{2} \mathrm{Me}$ in refluxing $\mathrm{CH}_{2} \mathrm{Cl}_{2}$ to yield the new complexes $(\mathrm{OC})_{4} \mathrm{Re}\left[\mu-\mathrm{C}(\mathrm{H})=\mathrm{C}\left(\mathrm{CO}_{2} \mathrm{Me}\right) \mathrm{C}(\mathrm{H})=\mathrm{C}\left(\mathrm{CO}_{2} \mathrm{Me}\right)\right] \mathrm{Re}(\mathrm{CO})_{5}, 7$, and $(\mathrm{OC})_{4} \operatorname{Re}\left[\mathrm{C}(\mathrm{H})=\mathrm{C}\left(\mathrm{CO}_{2} \mathrm{Me}\right) \mathrm{C}(\mathrm{H})=\mathrm{C}\left(\mathrm{CO}_{2} \mathrm{Me}\right) \mathrm{C}(\mathrm{H})=\mathrm{C}\left(\mathrm{CO}_{2} \mathrm{Me}\right)\right] \mathrm{Re}(\mathrm{CO})_{4}$, 8a-b that exists in solution as a mixture of isomers by the head - to - tail coupling of two and three $\mathrm{HC} \equiv \mathrm{CCO}_{2} \mathrm{Me}$ molecules, respectively. In complex 7 the two linked $\mathrm{HC} \equiv \mathrm{CCO}_{2} \mathrm{Me}$ groups form a four carbon chain between the metal containing groups. At $98^{\circ} \mathrm{C}, 8$ was transformed into 9 . One of the carboxylate substituents is also coordinated to form a five-membered metallacyclic ring. In complex $\mathbf{8 a}$ the metal containing groups are joined by a six carbon chain formed from the three alkynes, and two of the carboxylate groups are coordinated to form five and six-membered metallacyclic rings. The six carbon chain in 9 was cyclized to form a $2,4,6$-tri(methyloxycarbonyl)phenyl group that is $\sigma$-coordinated to the metal atom and also has one of its carboxylate groups coordinated to the metal. 
The Organic Chemistry of Dimetallated Olefin Complexes
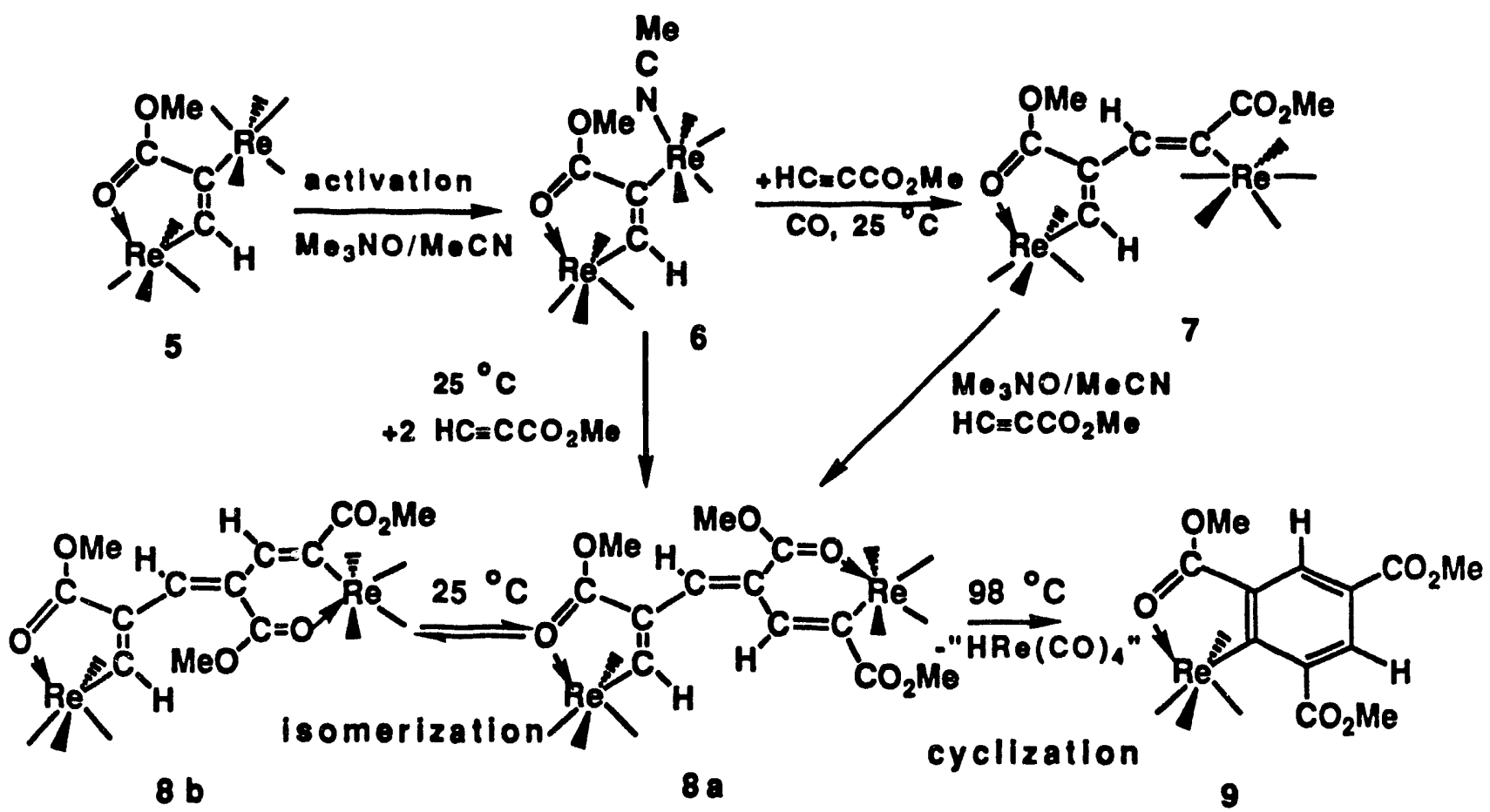

Scheme 2

Complex 6 reacts with arylisothiocyanates to yield a series of complexes having the general formula $\operatorname{Re}(\mathrm{CO})_{4}[E$ $\left.\mathrm{HC}=\mathrm{C}\left(\mathrm{CO}_{2} \mathrm{Me}\right) \mathrm{CN}(\mathrm{Ar})=\mathrm{S}\right] \mathrm{R} \theta(\mathrm{CO})_{4}, 10 \mathrm{a}, \mathrm{Ar}=\mathrm{p}$-tolyl; 10b, $\mathrm{Ar}=\mathrm{Ph} ; 10 \mathrm{c}, \mathrm{Ar}=$ p-chlorophenyl formed by the loss of NCMe and the addition and insertion of one isothiocyanate molecule into one of the metal - carbon bonds to form a thioamido group that is chelated to one of the rhenium atoms. Irradiation of the complexes $\operatorname{Re}(\mathrm{CO})_{4}\left[E-H C=C\left(\mathrm{CO}_{2} \mathrm{Me}\right) \mathrm{C}=\mathrm{N}\left(\mathrm{C}_{6} \mathrm{H}_{4}-\mathrm{p}\right.\right.$ $\mathrm{R}) \mathrm{S}] \mathrm{Re}(\mathrm{CO})_{4}, 10 \mathrm{a}-\mathrm{C}$ in the presence of iodine yielded a mixture of four products $\operatorname{Re}_{2}(\mathrm{CO})_{7}\left[\mu-2-\mathrm{S}, 3-\mathrm{CO}_{2} \mathrm{Me}, 6-\mathrm{R}, \mathrm{NC}_{9} \mathrm{H}_{4}\right](\mu-1), 11 \mathrm{a}-\mathrm{C}, \mathrm{R}=\mathrm{H}, \mathrm{Me}, \mathrm{Cl}$; $\operatorname{Re}(\mathrm{CO})_{4}\left[E-H C=C\left(C_{2} \mathrm{Me}\right) \mathrm{C}=\mathrm{N}\left(\mathrm{C}_{6} \mathrm{H}_{4}-\mathrm{p}-\mathrm{R}\right) \mathrm{S}\right] \mathrm{Re} \mathrm{e}_{2}(\mathrm{CO})_{7}(\mu-1), 12 \mathrm{a}-\mathrm{c}, \mathrm{R}=\mathrm{H}, \mathrm{Me}$, $\mathrm{Cl} ; \mathrm{Re}(\mathrm{CO})_{4}\left[\mathrm{E}-\mathrm{HC}=\mathrm{C}\left(\mathrm{CO}_{2} \mathrm{Me}\right) \mathrm{C}\left(\mathrm{NHC}_{6} \mathrm{H}_{4}-\mathrm{p}-\mathrm{R}\right)=\mathrm{S}\right] \mathrm{Re}(\mathrm{CO})_{4}(\mathrm{I}), 13 \mathrm{a}-\mathrm{C}, \mathrm{R}=\mathrm{H}, \mathrm{Me}$, $\mathrm{Cl} ;$ and $\mathrm{Re}(\mathrm{CO})_{4}\left(2-\mathrm{S}, 3-\mathrm{CO}_{2} \mathrm{Me}, 6-\mathrm{R}, \mathrm{NC}_{9} \mathrm{H}_{4}\right), 14 \mathrm{a}-\mathrm{C}, \mathrm{R}=\mathrm{H}, \mathrm{Me}, \mathrm{Cl}$ with the compounds 14 being the major products. UV irradiation of $10 \mathrm{~b}$ in the 
absence of iodine also yielded 14b, as the major product. Compounds 11 and 14 contain substituted quinoline-2-thiolate ligands formed by a cyclization reaction involving one of the carbon atoms of the aryl ring and the hydrogen-substituted carbon atom of the alkenyl group. The structures and interrelationships of these complexes are shown in Scheme 3.

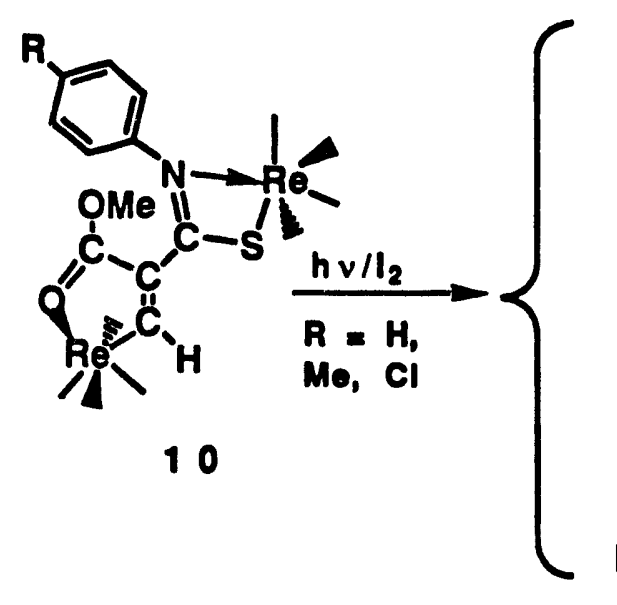

Scheme 3
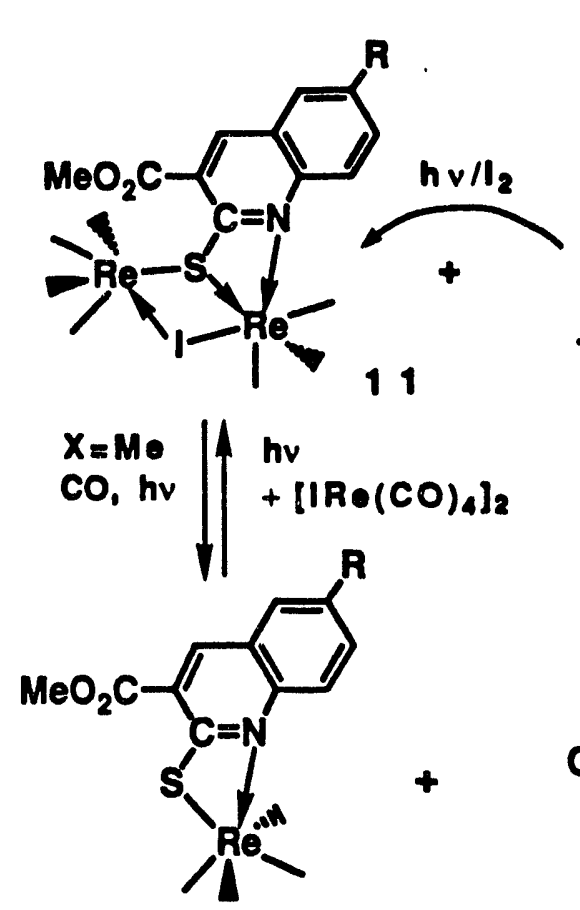

14
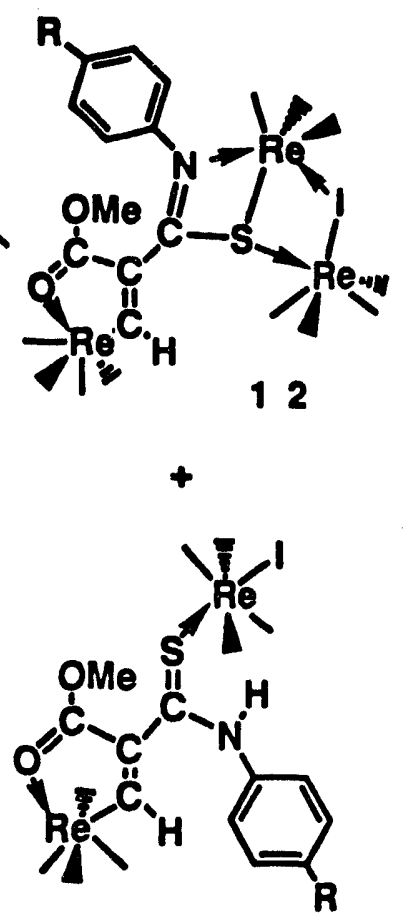

13

\section{2) Ring Opening of Cyclic Thioethers.}

In 1992 we had completed many of our investigations of the ring opening reactions of the strained four membered cyclic thioethers, thietanes by metal cluster complexes. In 1993 we extended our studies of these ring opening reactions to include the unstrained cyclic thioethers: tetrahydrothiophene (THT) $\left(\mathrm{SCH}_{2} \mathrm{CH}_{2} \mathrm{CH}_{2} \mathrm{CH}_{2}\right)$ and thiacyclohexane (TCH). We prepared the complex $\mathrm{Os}_{3}(\mathrm{CO})_{10}\left(\mathrm{SCH}_{2} \mathrm{CH}_{2} \mathrm{CH}_{2} \mathrm{CH}_{2}\right)_{2}, 15$ by the reaction of 
$\mathrm{Os}_{3}(\mathrm{CO})_{10}(\mathrm{NCMe})_{2}$ with tetrahydrothiophene (THT). When heated to $97^{\circ} \mathrm{C}$, 15 was transformed to the complex $\mathrm{Os}_{3}(\mathrm{CO})_{10}\left[\mu-\eta^{2}-\left(\mathrm{SCH}_{2} \mathrm{CH}_{2} \mathrm{CH}_{2} \mathrm{CH}\right)\right](\mu-$ $H$ ), 16 by loss of one THT ligand and the activation of a C-H bond on one of the methylene groups bonded to the sulfur atom. Most interestingly we found that at $125^{\circ} \mathrm{C}, 16$ was decarbonylated and transformed into the new compound $\mathrm{Os}_{3}(\mathrm{CO})_{9}\left[\mu-\eta^{3}-\mathrm{S}\left(\mathrm{CH}_{2}\right)_{2} \mathrm{CH}=\mathrm{CH}_{2}\right](\mu-\mathrm{H}), 17$ by a ring opening cleavage of one of the C-S bonds. Compound 17 contains a 3-butene thiolate ligand in which the sulfur atoms bridges one of the metal - metal bonds and the double bond is $\pi$-coordinated to one of the sulfur bridged metal atoms. An investigation of the transformation of $\mathrm{Os}_{3}(\mathrm{CO})_{10}[\mu$ $\left.\left(\mathrm{SCH}_{2} \mathrm{CD}_{2} \mathrm{CD}_{2} \mathrm{C} H\right)\right](\mu-\mathrm{H}), \quad 16-d_{4}$ to $\mathrm{Os}_{3}(\mathrm{CO})_{9}\left[\mu-\eta^{3}-\mathrm{SCH}_{2} \mathrm{CD}_{2} \mathrm{CD}=\mathrm{CH}_{2}\right](\mu-\mathrm{D})$, $17-d_{4}$ at $125^{\circ} \mathrm{C}$ showed that the hydride ligand was returned to the carbon atom from which it was initially cleaved and deuterium was shifted to the metal atoms. A variety of mechanisms are possible for this transformation, but the one considered most likely which involves the insertion of one of the metal atoms into the carbon - sulfur bond of a sulfur coordinated bridging THT molecule is shown in Scheme 4. 

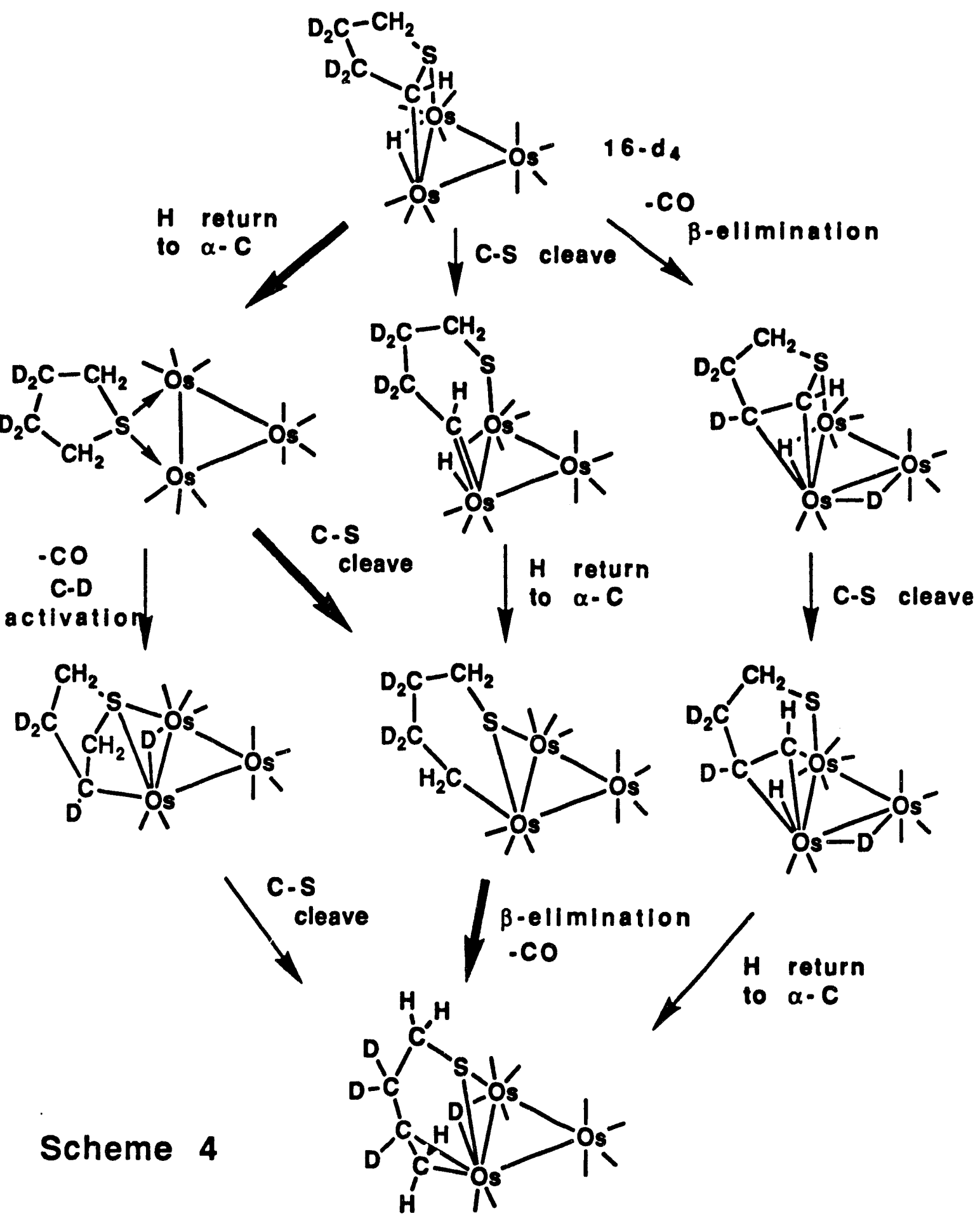
transformed into four new compounds: $\mathrm{Os}_{3}(\mathrm{CO})_{9}\left(\mu-\mathrm{SCH}_{2} \mathrm{CH}_{2} \mathrm{CH}_{2} \mathrm{CH}_{2} \mathrm{C}\right)(\mu-\mathrm{H})_{2}$, $19, \mathrm{Os}_{3}(\mathrm{CO})_{8}\left(\mu-\mathrm{SCH}_{2} \mathrm{CH}_{2} \mathrm{CH}_{2} \mathrm{CH}_{2} \mathrm{C}\right)\left[\mathrm{S}\left(\mathrm{CH}_{2}\right)_{5}\right](\mu-\mathrm{H})_{2}, \quad 20$, $\mathrm{Os}_{3}(\mathrm{CO})_{11}\left(\mathrm{SCH}_{2} \mathrm{CH}_{2} \mathrm{CH}_{2} \mathrm{CH}_{2} \mathrm{CH}_{2}\right), 21, \mathrm{Os}_{3}(\mathrm{CO})_{9}\left(\mu-\mathrm{SCH}_{2} \mathrm{CH}_{2} \mathrm{CH}_{2} \mathrm{CH}_{2} \mathrm{CH}\right)(\mu-\mathrm{H})$, 22 by heating to $97^{\circ} \mathrm{C}$. Compounds 19,21 and 22 were formed by the loss of one $\mathrm{TCH}$ ligand. In compounds 19 and 22 the remaining $\mathrm{TCH}$ ligand has undergone activation of two and one of the $\mathrm{CH}$ bonds, respectively, $\alpha$ to the sulfur atom, and the $\mathrm{TCH}$ ligand was transformed into a metallated triply bridging ligand. Compounds 19 and 22 are interconvertible isomers. The structures and interrelationships of these compounds are shown in Scheme 5. In contrast to our previous investigations of all cyclic thioethers, we have found no evidence for ring opening reactions yet. This may be due to the lack of strain in the larger TCH molecule.

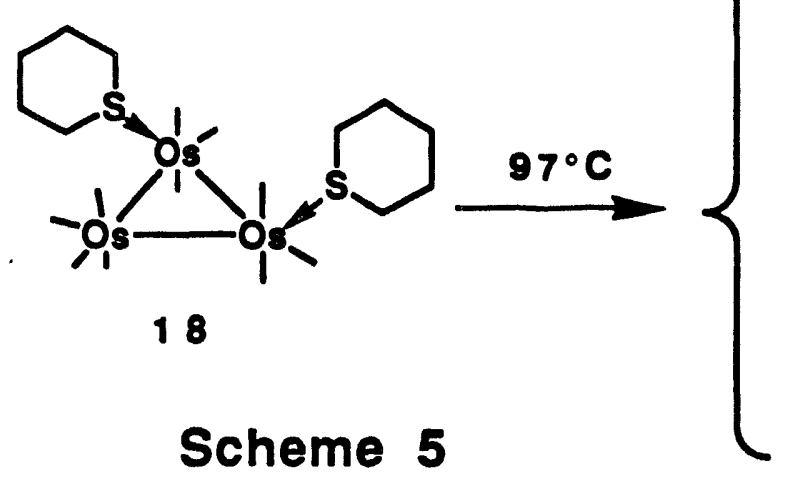

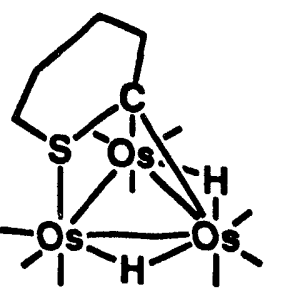

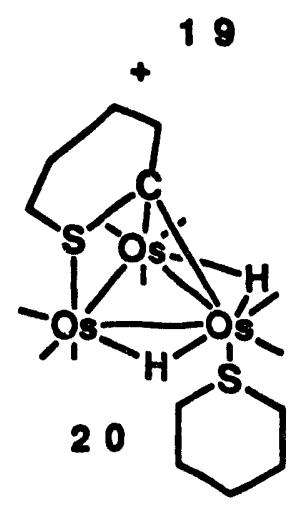

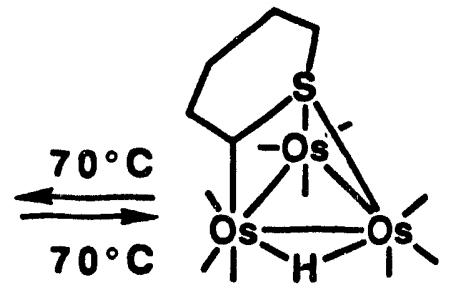

22
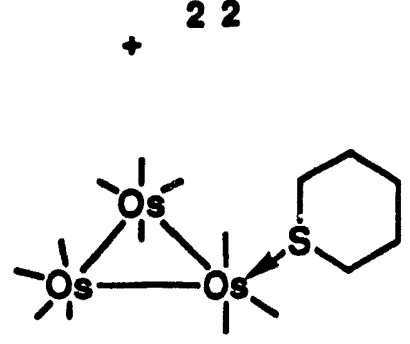

21

\section{3) Studies of the Cyclobutyne Ligand.}

In order to expand upon our understanding of the transformations of strained ring heterocycles in metal cluster complexes, we decided that it 
would be necessary to investigate the chemistry of the corresponding carbocycles. In 1992 we prepared and structurally characterized the first stabilized form of the molecule, cyclobutyne, $\mathrm{C}=\mathrm{CCH}_{2} \mathrm{CH}_{2}$ by stabilization through complexation to a cluster of three osmium atoms. In 1993 we had great sucess in preparing new examples of these complexe and in studying the chemical and physical properties of these new ligands. In particular, we prepared the first dialkyl substituted cyclobulyne ligand $\overline{\mathrm{C}_{2} \mathrm{CH}_{2} \mathrm{C}}(\mathrm{Me})^{t} \mathrm{Bu}$. The reaction of 4-t-butyl-4-methyl-1-phenylthiocyclobutene with $\mathrm{Os}_{3}(\mathrm{CO})_{10}(\mathrm{NCMe})_{2}$ yielded the new complex $\mathrm{Os}_{3}(\mathrm{CO})_{10}[\mu-$ $\left.\mathrm{PhSC} \mathrm{C}_{2} \mathrm{CH}_{2} \mathrm{C}(\mathrm{Me})^{t} \mathrm{Bu}\right](\mathrm{m}-\mathrm{H}), 23$ by displacement of the MeCN ligands and an addition of the 4-t-butyl-4-methyl-1-phenylthiocyclobutene that included the activation of the alkenyl $\mathrm{CH}$ bond. Compound 23 was decarbonylated to yield the new compound $\mathrm{Os}_{3}(\mathrm{CO})_{9}\left[\mu_{3}-\mathrm{SPh}_{2} \mathrm{C}_{2} \mathrm{CH}_{2} \mathrm{C}(\mathrm{Me})^{t} \mathrm{Bu}\right](\mu-\mathrm{H}), 24$ in which the alkenyl double bond of the metallated cyclobutenyl ligand has become coordinated to the cluster. When heated to $125^{\circ} \mathrm{C}$ compound 24 was

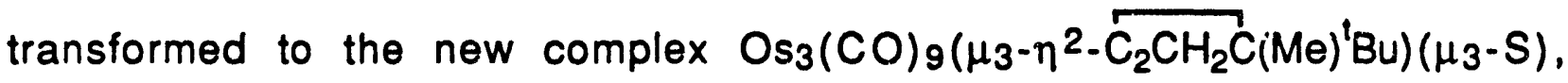
25 which contains a triply bridging 3,3-methyl-t-butylcyclobutyne ligand formed from the metallated cyclobutenyl ligand by cleavage from the sulfur atom in 24. The phenyl group was also cleaved from thie sulfur atom resulting in formation of a triply bridging sulfido ligand. The phenyl group and hydride ligand were eliminated, presumably as benzene. All of these products were characterized crystallographically and the structures and interrelationships of the compounds are shown in Scheme 6. 


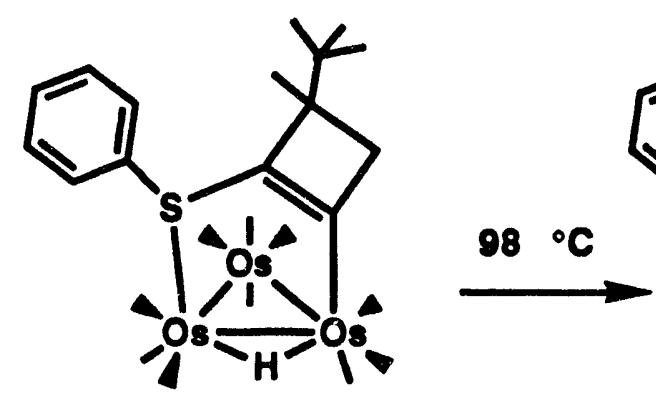

23

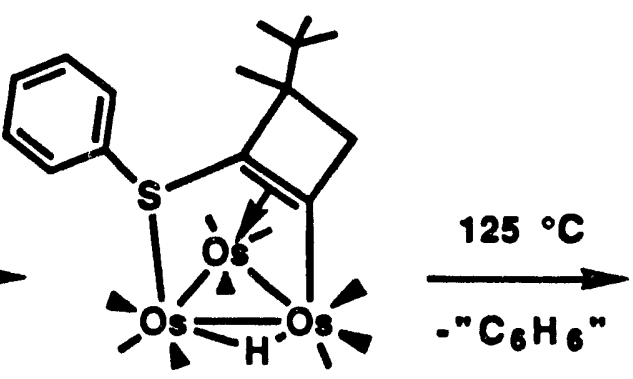

24

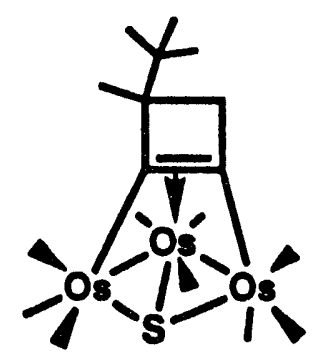

25

\section{Scheme 6}

We also prepared the first example of a quadruply bridging cyclobutyne ligand from the reaction $\mathrm{Ru}_{3}(\mathrm{CO})_{12}$ with 4-t-butyl-4-methyl1-phenylthio-cyclobutene. This reaction actually yielded four new complexes: $R u_{4}(C O)_{12}\left[\mu_{4}-S C_{2} C_{2} C(M e)^{i} B u\right], 26 ;\left\{R u_{3}(C O)_{8}\left[\mu_{3}-\eta^{2}\right.\right.$. $\left.\left.\widehat{\mathrm{C}_{2} \mathrm{CH}_{2} \mathrm{C}}(\mathrm{Me})^{t} \mathrm{Bu}\right]\left(\mu_{4}-\mathrm{S}\right)\right\}_{2}, 27 ; \mathrm{Ru}_{4}(\mathrm{CO})_{11}\left[\mu_{4}-\eta^{2}-\overline{\mathrm{C}}_{2} \mathrm{CH}_{2} \mathrm{C}(\mathrm{Me})^{t} \mathrm{Bu}\right]\left(\mu_{4}-\mathrm{S}\right), 28$, and a trace of the hexanuclear complex $\mathrm{Ru}_{6}(\mathrm{CO})_{16}\left[\mu_{4}-\mathrm{CCHCH}=\mathrm{C}(\mathrm{Me})^{t} \mathrm{Bu}\right]\left(\mu_{4}\right.$ S), 29. All four products were characterized by single crystal $x$-ray diffraction analyses. Compounds 27 and 28 contain the disubstituted cyclobutyne ligand $\widehat{\mathrm{C}_{2} \mathrm{CH}_{2} \mathrm{C}}(\mathrm{Me})^{\mathrm{t}} \mathrm{Bu}$ formed by the cleavage of the hydrogen atom and the phenylthio group from the cyclobutene ring. Compound 26 contains a quadruply bridging metalated cyclobutenylthiolato group. It was transformed to compound 28 which contains the first example of a quadruply bridging cyclobutyne ligand. Compound 29 contains six ruthenium atoms arranged in the shape of an edge bridged square pyramidal cluster. A sulfido ligand bridges the square base and a

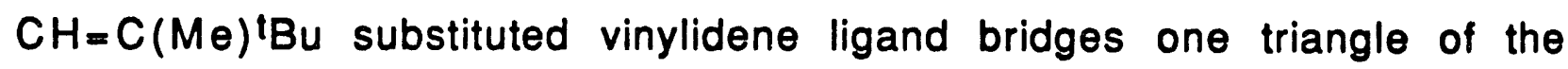
square pyramid and the edge bridging ruthenium atom. Compound 27 is a dimer that can be split by reaction with $\mathrm{CO}$ to yield two of the monomeric triruthenium cluster complexes $\mathrm{Ru}_{3}(\mathrm{CO})_{9}\left[\mu_{3}-\eta^{2}-\mathrm{C}_{2} \mathrm{CH}_{2} \mathrm{C}(\mathrm{Me})^{t} \mathrm{Bu}\right]\left(\mu_{3}-\mathrm{S}\right), 30$. 
Compound 30 is the ruthenium homologue of 25 . The structures and interrelationships of these compounds are shown in Scheme 7.

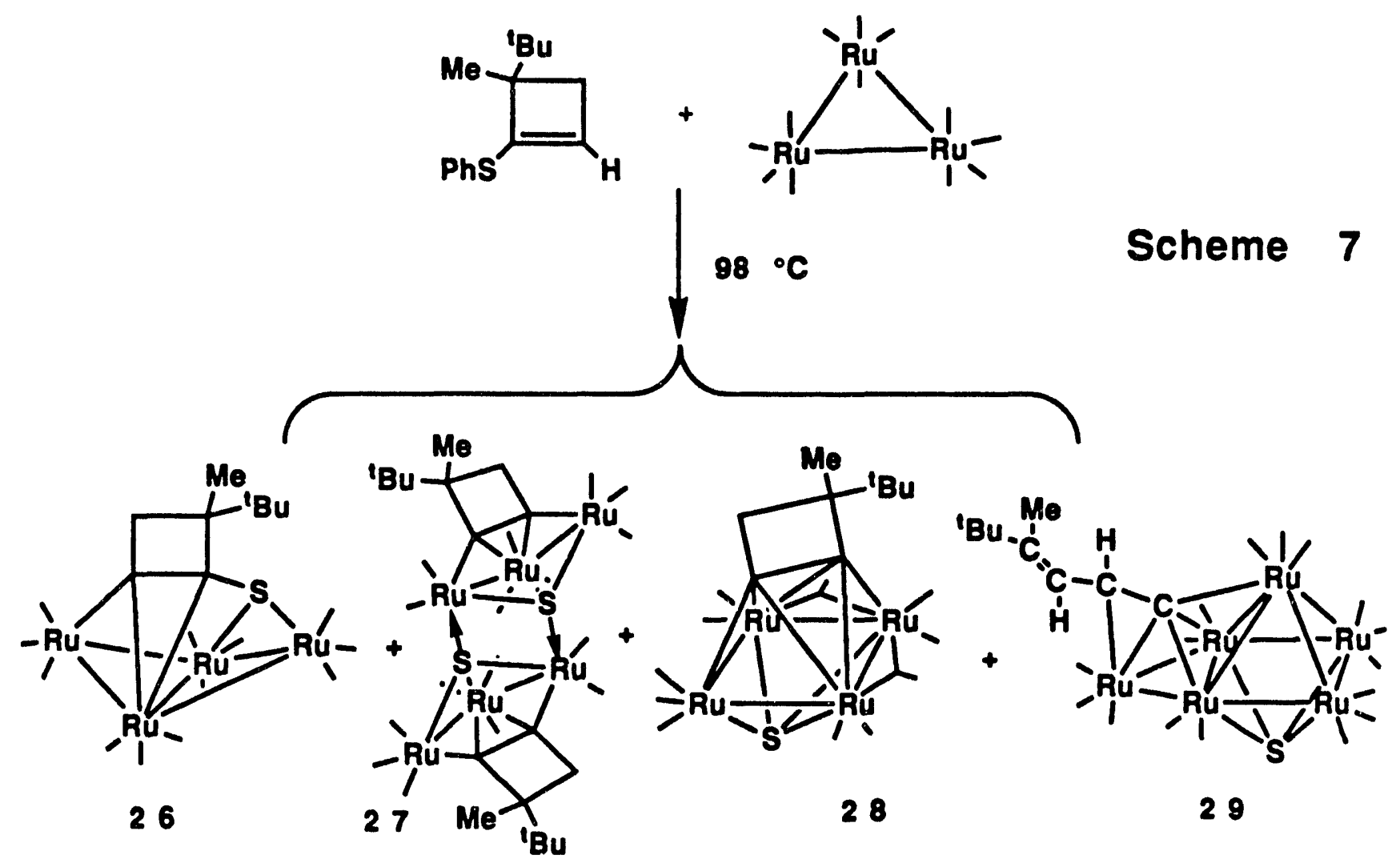

\section{4) Energy Storage by Metal Clusters.}

In 1993 we discovered a new energy capture and storage process that involves a metal cluster complex. UV-vis irradiation of the cluster complex $\mathrm{PtOs}_{3}(\mathrm{CO})_{10}\left(\mu-\eta^{2}-\mathrm{dppm}\right)\left[\mathrm{Si}(\mathrm{OMe})_{3}\right](\mu-H), 31$, dppm = bis(diphenylphosphino)methane, produced a metastable energy-rich complex that only slowly released its energy by returning to the ground state. Both the original metal complex and its metastable isomer were stable enough to be fully characterized by single crystal $x$-ray diffraction analyses. Complex 31 was found to consist of a planar butterfly cluster of four metal atoms with the platinum atom located in one of the "hinge" 
sites. Its isomer 32 was formed by irradiation for $6 \mathrm{~h}$. Compound 32 only slowly converts back to 31 thermally, $\Delta H^{*}=24.3 \mathrm{kcal} / \mathrm{mol}, \Delta S^{*}=6.0 \mathrm{eu}$. Its half-life is $4.6 \mathrm{~h}$ at $47^{\circ} \mathrm{C}$. The structure of 32 also consists of a planar PtOs3 butterfly cluster of four metal atoms, but in contrast to 31 the platinum atom lies in a wingtip site of the cluster.

The transformation of of 31 to 32 occurred by a rearrangement of the metal - metal bonding. This is believed to have occurred by a transition through a tetrahedral-like intermediate $\mathbf{A}$ by the formation of a bond between the wingtip metal atoms Os(2) and Os(3) in 31, see Scheme 8. In $A$ all of the metal atoms would obey the 18 electron rule. Although the transformation produces almost no side products, the quantum yield for the transformation of 31 to 32 measured at $345 \mathrm{~nm}$ was unfortunately very low, 0.003

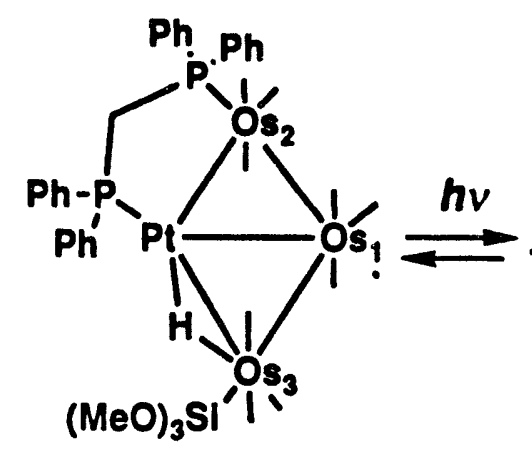

31

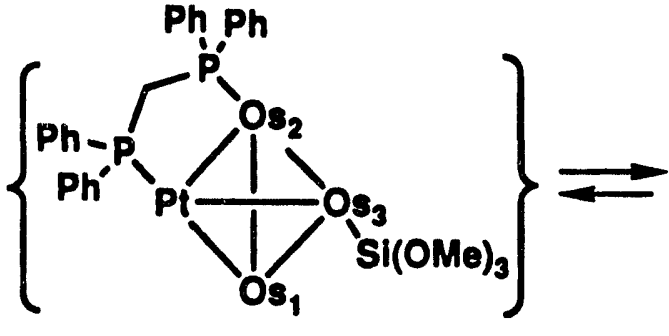

A

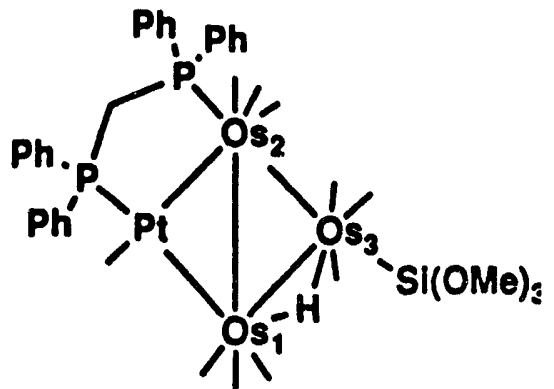

32

\section{Scheme 8}

The most important feature of this study is that it demonstrates for the first time that a metal cluster complex can capture and store energy by undergoing a transformation to a metastable species. Materials that can efficiently capture photon energy and then release it thermally after 
an appreciable delay could, in principle, be of value in energy conversion and solar energy storage processes.

B) Studies planned for the next budget year.

1) Insertion of an Alkynes into Metal - metal Single Bonds and new Organic Chemistry of Dimetalated Olefins.

It is planned to search for new examples of the insertion of alkynes into metal-metal bonds of dinuclear complexes of Group VIIB. In particular, we shall investigate the reactions of dimanganese carbonyl complexes with alkynes containing electron withdrawing groups. $\mathrm{Mn}_{2}(\mathrm{CO})_{9}(\mathrm{NCMe})$, the manganese homologue of 1 , would a good starting point for these studies. We will also examine the reactions of $\mathrm{Mn}_{2}(\mathrm{CO})_{10}$. Since we have achieved success with the alkyne, $\mathrm{EtO}_{2} \mathrm{CC} \equiv \mathrm{CCO}_{2} \mathrm{Et}$, alkyne dicarboxylates, $\mathrm{RO}_{2} \mathrm{CC} \equiv \mathrm{CCO}_{2} \mathrm{R}, \mathrm{R}=\mathrm{Me}$, Et, etc. would be some of the first to study. We have already obtained some interesting results on the reactions of $\mathrm{Mn}_{2}(\mathrm{CO})_{9}(\mathrm{NCMe})$ with $\mathrm{HC} \equiv \mathrm{CCO}_{2} \mathrm{Me}$ and $\mathrm{HC} \equiv \mathrm{COEt}$.

Complexation to metals has been an important mechanism for activating and modifying alkynes. Dimetalated olefins are also metal activated alkynes. We plan to investigate the organic chemistry of dimetalated olefins further through coupling reactions of small unsaturated molecules, such as $C O$ and selected cumulenes $R N=C=O$, $R N=C=S, S=C=S$, etc to the alkyne using insertion reactions into the metal - carbon bonds. It may be possible to prepare complex new organic molecules if these coupling reactions can be accomplished.

2) Studies of the Cyclobutyne Ligand.

Our studies of the synthesis of cyclobutyne ligands has been focused on the use of cyclobutenylthioethers and is dependent on the facile cleavage of the carbon-sulfur bond to introduce the cyclobutenyl grouping 
into the complex. In future studies we are planning to investigate the reactivity of other cyclobutenes ( $\theta$. g. unsubstituted cyclobutenes and halogen substituted (X) cyclobutenes) as possible reagents.
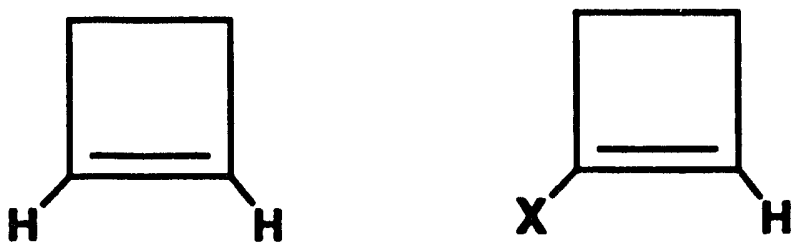

Cyclobutynes have not yet been isolated as free molecules. Presumably, they possess too much ring strain and thus spontaneously decompose by opening their rings. With this in mind we are planning to investigate the ring opening reactions of our cluster stabilized cyclobutynes to see if we can identify any characteristic bond rupture processes that might provide an understanding for the instability of free cyclobutyne molecules. We will attempt to open the cyclobutyne rings in our complexes by thermal and photochemical treatments. The nature of the transformations will be estabished in part by crystallographic characterization of the products.

\section{3) Energy Storage in Metal Clusters.}

In 1993 we discovered a unusual mechanism of energy storage in a molecular complex. This was based upon the photoexcitation of the tetranuclear mixed metal complex, $\mathrm{PtO} s_{3}(\mathrm{CO})_{10}\left(\mu-\eta^{2}-\mathrm{dppm}\right)\left[\mathrm{Si}(\mathrm{OMe})_{3}\right](\mu-$ $H$ ) and its conversion to an energy rich isomer by a rearrangement of the metal - metal bonding. Curiously, the energy rich isomer rearranges back to the more stable isomer thermally only over a period of several hours at room temperature, see preceding progress report.

For 1994 we are planning to conduct a search for additional examples of this unusual energy capture and storage phenomenon. Our 
structural studies have shown that the energy storage behavior is based on the formation of a new arrangement of the metal - metal bonds that cannot readily rearrange back to the original lower energy configuration (i. e. the energy rich isomer is a kinetically stable, but not thermodynamically the most form of the complex). Since the phenomenon is based on mixed metal clusters containing butterfly tetrahedral arrangements of four metal atoms, our search will be based on clusters of these types. The molecules with the greatest chances for success would be those most similar to the one we have already studied, $\mathrm{PtOs}_{3}(\mathrm{CO})_{10}(\mu$ $\eta^{2}$-dppm)[Si(OMe) $]$ ] $(\mu-H)$. For example, derivatives formed by substitution of some of the CO ligands with phosphines will be some of the first try. Modifications of the silyl or dppm ligand would be other possibilities. Changes in the identity and composition of the metal atoms are other possibilities.

\section{C) Publications Under This Project In 1993.}

1. R. D. Adams and M. P. Pompeo, Controlled Oxidative Degradation of the Triosmium Carbonyl Cluster Complex Os3(CO) $10[\mu$ $\left.\left(\mathrm{SCH}_{2} \mathrm{CMe}_{2} \mathrm{CH}_{2}\right)_{3}\right]$, Organometallics 12, 951 (1993).

2. R. D. Adams, L. Chen and W. Wu, The Reaction of Alkynes with Electron Withdrawing Substituents with $\operatorname{Re}_{2}(\mathrm{CO})_{9}(\mathrm{NCMe})$. The Formation of Trans-Dimetallated Olefins by Alkyne Insertion into an Re-Re Bond, Organometallics, 12, 1257 (1993).

3. R. D. Adams, L. Chen and W. Wu, Facile Alkyne Coupling Reactions in Dirhenium Carbonyl Complexes, Organometallics, 12, 1623 (1993).

4. R. D. Adams and G. Chen, The Coordination and Activation of Azetidine by a Triosmium Cluster, Organometallics, 12, 2070 (1993). 
5. R. D. Adams, G. Chen, L. Chen and J. Yin, The Reactions of $\mathrm{Mn}_{2}(\mathrm{CO})_{9}(\mathrm{NCM} \theta)$ with Alkynes Containing Electron Donating Substitutents, Organometallics, 12, 2644 (1993).

6. R. D. Adams, G. Chen, X. Qu, W. Wu and J. H. Yamamoto, Cyclobutyne Ligands. I. The Synthesis and Reactivity of a Cyclobutyne Ligand in a Triosmium Complex including a Structural Characterization of the First Cyclobutyne Ligand in the Complex Os $3(\mathrm{CO})_{9}\left(\mu-\eta^{2}\right.$ $\left.\mathrm{C}_{2} \mathrm{CH}_{2} \mathrm{CH}_{2}\right)(\mu-\mathrm{SPh})(\mu-\mathrm{H})$, Organometallics, 12, 3029 (1993).

7. R. D. Adams, L. Chen and W. Wu, A New Route to Substituted Quinoline-2-thiolate Ligands by the Coupling and Cyclization of Arylisothiocyanates to Alkyne Ligands, Organometallics, 12, 2404 (1993).

8. R. D. Adams, G. Chen, X. Qu, and W. Wu, Cyclobutyne Ligands. II. Reactions of the Cyclobutyne Triosmium Complex Os ${ }_{3}(\mathrm{CO})_{9}\left(\mu-\eta^{2}\right.$. $\left.\mathrm{C}_{2} \mathrm{CH}_{2} \mathrm{CH}_{2}\right)(\mu-\mathrm{SPh})(\mu-\mathrm{H})$ with Diphenylacetylene, Organometallics, 12, 3426 (1993).

9. R D. Adams, M. P. Pompeo, W. Wu and J. H. Yamamoto, Formation of Butenethiolate by the Ring Opening of Tetrahydrothiophene by a Triosmium Cluster Complex, J. Am. Chem Soc. 115, 8207 (1993).

10. R. D. Adams, G. Chen, L. Chen, W. Wu and J. Yin, Coupling of CO to $\mathrm{HC} \equiv \mathrm{COEt}$ in Dimanganese Carbonyl Complexes, Organometallics, 12, 3431 (1993).

11. R. D. Adams and J. E. Cortopassi, Energy Capture by a Tetranuclear Metal Cluster Complex and the Isolation and Structural Characterization of its Metastable Photoproduct. Studies of PtOs $\left._{3}(\mathrm{CO})_{10}\left(\mu-\eta^{2}-d p p m\right)\left[\mathrm{Si}_{(\mathrm{OMe})}\right)_{3}\right](\mu-\mathrm{H})$ and its Photoisomer, J. Am. Chem Soc. 115, 8877 (1993).

12. R. D. Adams, L. Chen and W. Wu, Alkyne Coupling Reactions in Dimanganese Carbonyl Complexes. The Reactions of $\mathrm{Mn}_{2}(\mathrm{CO})_{9}(\mathrm{NCMe})$ with $\mathrm{HC} \equiv \mathrm{CCO}_{2} \mathrm{Me}$, Organometallics, 12, 4112 (1993). 
13. Richard D. Adams, Xiaosu Qu, and Wengan Wu, Cyclobutyne Ligands. III. The Synthesis and Characterization of a Disubstituted Cyclobutyne Ligand in the Triosmium Complex Os $\mathrm{s}_{3}(\mathrm{CO})_{9}\left(\mu_{3}-\eta^{2}\right.$. $\left.\widehat{\mathrm{C}_{2} \mathrm{CH}_{2} \mathrm{C}}(\mathrm{Me})^{\mathrm{t}} \mathrm{Bu}\right)\left(\mu_{3}-\mathrm{S}\right)$, Organometallics, 12, 4117 (1993).

14. R. D. Adams, L. Chen and W. Wu, The Transformation of Alkenyl-NArylthioamido Ligands into Quinoline-2-thiolate Ligands in Dirhenium Carbonyl Complexes, Organometallics, 12, 4962 (1993).

15. R D. Adams, J. E. Cortopassi, J. H. Yamamoto and W. Wu, Transformations of Thiacyclohexane by a Triosmium Cluster, Organometallics, 12, 4955 (1993).

(D) Current and Pending Support.

(a) Current:

Agency Title Period Annual Amount

1) DOE The Transformations of Organic Amines by Transition Metal Cluster

1 year $\$ 115,000$ Compounds

2) NSF The Chemistry of Heteronuclear Metal 1 year Cluster Complexes

$\$ 97,000$ Cluster Complexes

3) PRF Studies of the Coordination and RIng Opening Reactions of Strained Ring 1 year $\$ 20,000$ Thioethers with Metal Carbonyl Cluster Complexes

(b) Pending:

Total Amount
1) PRF Studies of the Coordination and RIng 3 years $\$ 75,000$ Opening Reactions of Saturated Cyclic Thioethers by Metal Carbonyl Cluster Complexes

(E) Statement of Residual Funds.

It is estimated that there will be no funds remaining ar the end of the current budget year. 

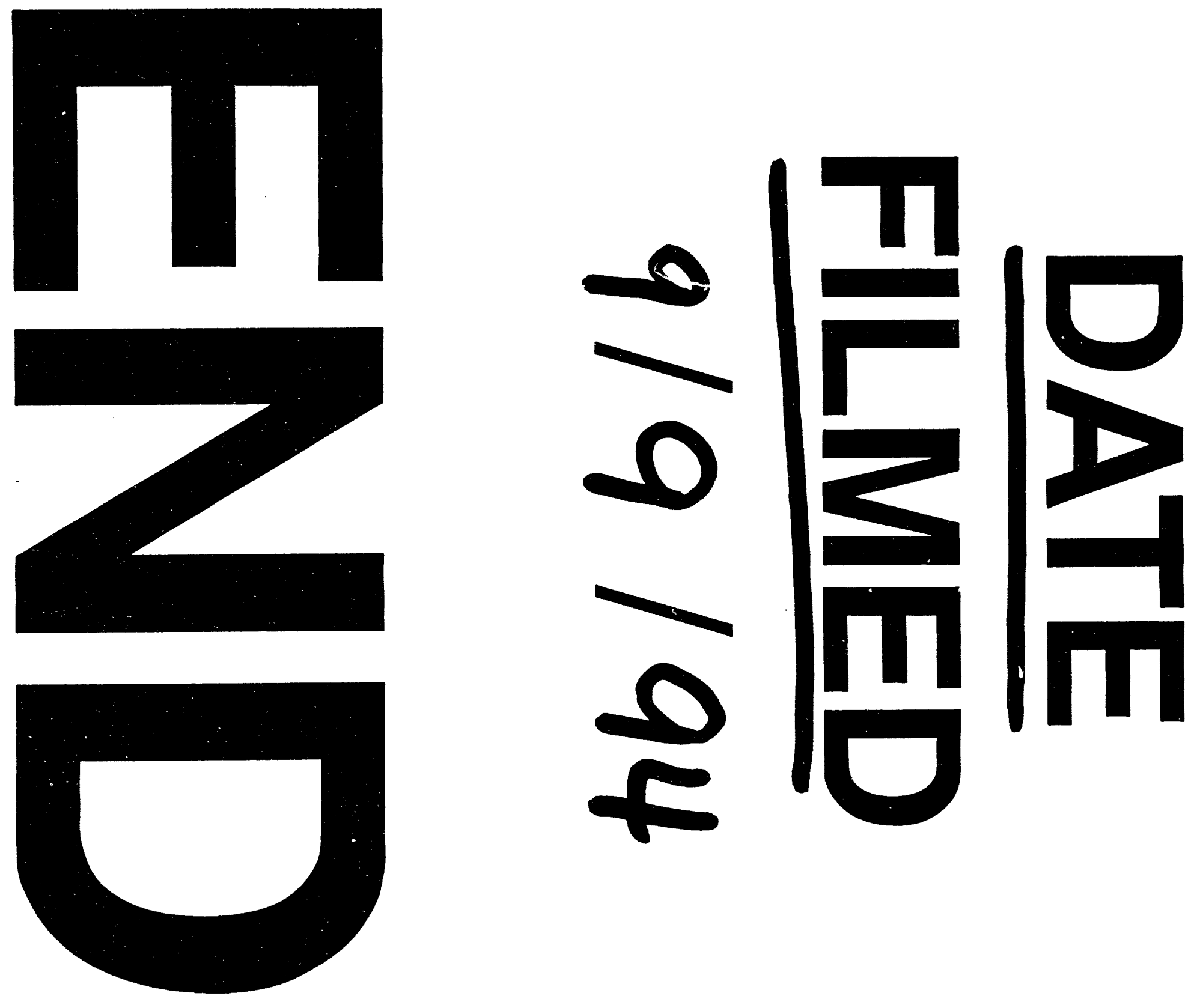


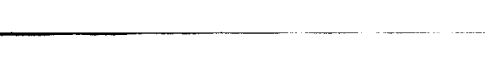

(1) 